\title{
Primacy of memory linkage in choice among valued objects
}

\author{
GREGORY V. JONES \\ University of Warwick, Coventry, England \\ and \\ MARYANNE MARTIN \\ University of Oxford, Oxford, England
}

\begin{abstract}
Three psychological levels at which an object may be processed have been characterized by Norman (2004) in terms of the object's appearance, its usability, and its capacity to elicit memories. A series of experiments was carried out to investigate participants' choices among valued objects recalled in accordance with these three criteria. It was found consistently that objects selected for their capacity to elicit memories-here termed mnemoactive objects-were valued significantly more than the other objects. Even the financial or social importance of an object was outweighed by the importance of its memory link; possible implications for the economic analysis of subjective well-being are briefly discussed. The same pattern of mnemoactive dominance was found across age and gender. Appropriate choice of objects may allow an individual to exert a degree of indirect voluntary control over the activation of involuntary autobiographical memories, providing a new perspective on Proust's approach to memory.
\end{abstract}

Despite many advances in the field of autobiographical memory, one important area within it has still received relatively little systematic investigation, that of the relation between memory processes and the physical objects in our everyday human environment - telephones or toys, vehicles or vases. In an early series of experiments, we studied how one element of an object (e.g., its color) could act as a retrieval cue for another element (e.g., its location), using photographs of real objects such as cups and bottles (see, e.g., Jones, 1976, 1978). In a more recent series, we have focused on distortions of memory for the appearance of everyday objects such as road signs or cell phones (e.g., Jones \& Martin, 2004; Martin \& Jones, 1998, 2006, 2007). However, such studies have accepted the occurrences of certain objects in the environment as a given, and have focused on exploring their mnemonic consequences. What the studies have not done is to examine whether or not the mnemonic processing elicited by certain objects might account for their being present in the environment in the first place; it is this possibility which is explored in the present article. To avoid the circumlocution of referring repeatedly to objects which elicit mnemonic processing, we refer to them here as mnemoactive objects. ${ }^{1}$

We thank Don Norman, Kit Pleydell-Pearce, and David Rubin for helpful comments, and Katie Birkland, Lauren Davis, and Carrigan Denny-Brown for their assistance with testing and data analysis in Experiment 3. Correspondence may be addressed to G. V. Jones, Department of Psychology, University of Warwick, Coventry CV4 7AL, England (e-mail: g.v.jones@warwick.ac.uk).

Note-This article was accepted by the previous editorial team, when Colin M. MacLeod was Editor.
The roles played in relation to human memory by a small number of everyday objects, such as diaries or calendars, are relatively clear. In most cases, however, the situation is more complicated. The object's potential influence upon memory is often confined to a single person or to a restricted group of people (e.g., a single family), whose previous experiences happen to relate to the object in some way. For example, a particular coffee mug may stimulate similar perceptual processes in different people who observe it and similar motor processes in different people who use it, but may stimulate unique memory processes in the individual who received it as a gift. It is perhaps the highly individualized character of mnemoactive objects which has led to their relative neglect within psychology. Methodologically, this means that what is needed is to investigate the processing of a single class of objects defined by the consistency of mapping from each object to each participant. The procedure is conceptually slightly more complicated than the more usual one of investigating the processing of a single object (or set of objects) across different participants, and this has perhaps discouraged previous exploration of mnemoactive objects. Does this neglect matter? There are a number of reasons to believe that it does.

First, the relative neglect of personal objects within the psychology of memory contrasts with the considerable attention paid to public objects within cognate disciplines. There, the role of monuments and memorials in shaping (or attempting to shape) specific aspects of what people remember and think has been analyzed extensively (e.g., Choay, 2001; Michalski, 1998).

Second, everyday objects play an important role in reminiscence therapy, which "involves the sharing of memories often evoked through the use of stimulating material 
such as old pictures, songs, household items and newspapers" (Brooker \& Duce, 2000, p. 354). Reminiscence therapy appears to be an effective treatment for depressive symptoms among elderly people (Bohlmeijer, Smit, \& Cuijpers, 2003). However, Cappeliez, O'Rourke, and Chaudhury (2005) have reported that some forms of reminiscence, such as the revival of old problems, may be associated with relatively negative facets of mental health, again suggesting the need for a fuller understanding of memory evocation by everyday objects.

Third, the work of Berntsen and colleagues (e.g., Berntsen, 1998; Berntsen \& Hall, 2004) has demonstrated a pressing need to explore the processing of involuntary autobiographical memories. Unlike the voluntary memories which have been the usual subject of study in the area of autobiographical memory, such memories are not preceded by any conscious attempt at retrieval, and there appear to be important functional differences between the two. In particular, involuntary memories are considerably more likely than voluntary ones to refer to specific episodes rather than to summarized events, a distinction which acquires particular significance from Williams's proposal of an association between memory overgeneralization and emotional disorder (Williams 1996; Williams, Healy, \& Ellis, 1999; see also Jones, 2002). Further, the contrast between voluntary (or intentional) and involuntary memories is of central importance in the context of posttraumatic stress disorder (e.g., Ehlers \& Clark, 2000; Isaac, Cushway, \& Jones, 2006), where it has been encapsulated by Brewin, Dalgleish, and Joseph (1996) in a distinction between verbally accessible memories, which are relatively open to subsequent editing, and situationally accessible memories, which are not. What is of particular interest in the present context is the consistent finding that involuntary autobiographical memories are most frequently elicited by identifiable aspects of a person's physical surroundings. Across three earlier diary studies tabulated by Berntsen and Hall (2004), external cues of this type were identified for $65 \%$ of all recorded involuntary memories. Given the frequency and distinctive character of such memories, it appears important to discover whether involuntary memories can to some degree be placed under voluntary control. Despite the superficial paradox inherent in the idea of voluntary influence upon involuntary memories, the possibility to be explored here is that humans do indeed manipulate their environments in order to achieve some such control; that is, people may avoid relying only on voluntary memories by ensuring the inclusion in their surroundings of physical objects which can instigate involuntary memories. In this context, it is relevant to note that Marcel Proust's $A$ la recherche $d u$ temps perdu (Remembrance of things past) can be viewed as an extended argument not only for the central importance of involuntary memory processes, but also for the role of mnemoactive objects in modulating these processes. We will return later to a brief discussion of the implications for Proust's work of the present results.

The final reason for focusing on the mnemoactive properties of objects is provided by the recent work of Nor- man (2004). In his original classic work on the relations between objects and psychological processes, Norman (1988) pointed to the emphasis (indeed, overemphasis) by objects' designers on their appearances, as opposed to their uses. Since then, the issue of object usability has indeed been widely explored, especially in the area of human-computer interaction (e.g., Barnum, 2002; Gillan $\&$ Bias, 2001). Norman (2004) has argued, however, that it is essential to construct not a dichotomy but a trichotomy of objects and associated psychological processes. Object appearance is associated with reactive processing, and object usability is associated with behavioral processing, but the potential for objects to evoke memories is associated with reflective processing. Furthermore, Norman (2004, p. 46) proposed that the last of these factors is of the greatest psychological importance: "What do people love and cherish, despise and detest? Surface appearance and behavioral utility play relatively minor roles. Instead, what matters is the history of interaction, the associations that people have with the objects, and the memories they evoke." Thus, far from an object's linkage to memory being as peripheral as its relative neglect within psychology would suggest, Norman's theorizing implies that such linkage is of primary importance in determining object value.

In the present article, we seek to examine Norman's hypothesis empirically by comparing the characteristics of objects whose primary influences are exerted at the three different psychological levels he distinguished. As noted previously, experimental uniformity has to be imposed in terms of the investigation of uniform object-participant mappings, rather than in terms of a uniform set of object stimuli, and therefore the initial stage is to identify objects with the relevant mappings for each participant; the characteristics of each object can then be probed. In particular, we focus on the hypothesis that it is among objects which elicit mnemonic processing that a person's most valued possessions are to be found, rather than among objects which are distinguished for the reactive or behavioral processing which they elicit.

Of course, objects are often assessed according to societally mediated criteria rather than individualistic psychological criteria, and it is, therefore, informative to consider these also. Indeed, in commerce the widespread default assumption is that financial worth dominates considerations of value. Similarly, within the field of psychology there has been much exploration of the ways in which people choose among different options that are defined in financial or quasi-financial terms (see Shafir \& LeBoeuf, 2002) according to which people choose among different options. Accordingly, in the present investigation of how people choose among options that are defined in terms of objects' different forms of psychological influence on individuals, we will also consider the social and financial importance of the objects. If it turns out that people's choices among objects are systematically influenced by the objects' capacity to evoke memories, an understanding of this phenomenon may be of importance not only in psychology but also in economics, perhaps throwing some light on the remarkably weak relationship observed between wealth and hap- 
piness within a society (e.g., Easterlin, 2003; Frederick \& Loewenstein, 1999).

There were two phases in the procedure of each of the following experiments. First, in the recall phase, each participant recalled a number of objects on the basis of such criteria as their usability, and was probed about such characteristics of each object as its financial importance. Second, in the choice phase, the participant put in order all the recalled items in terms of their personal value.

In each experiment, a different number of objects was recalled and put in order of personal value. However, if an object is chosen as the $i$ th response among $n$ objects, a convenient empirical index of its personal value can be defined as $v(i, n)=(n-i) /(n-1)$. It can be seen that, for all $n \geq 2$, the outcomes of this linear transform of $i$ possess a unit range, from $v=0$ iff $i=n$, to $v=1$ iff $i=1$. That is, a measure of the personal importance of an individual's objects is derived here from that person's sequence of choices, with the resulting object value, $v$, ranging from 0 for the last-chosen object to 1 for the first-chosen object, irrespective of the specified number of objects.

Analyses of the responses in these experiments should therefore allow two linked questions to be addressed. First, do objects which are selected according to different psychological criteria within the recall phase differ systematically in value within the choice phase? Second, across all recalled objects, which object properties predominate in determining people's choices? For example, is the personal value of an object influenced more by its financial importance or by its mnemonic importance?

\section{EXPERIMENT 1}

In this experiment, each participant recalled a set of four objects. For three of these, the object was the one which the participant most valued because of its appearance, its usability, or its linkage to memory. In each case, participants were provided with examples of members of the relevant category, taken from Norman (2004). In addition to these three restrictive criteria, an additional object was selected with an unrestricted remit, in order to encompass the whole range of participants' most valued objects.

\section{Method}

Participants. There were 74 participants (61 female), final-year students at the Universities of Warwick and Oxford. Mean age was 21.2 years $(S D=1.6)$.

Design and Procedure. Participants worked their way through individual response booklets anonymously and at their own pace. In the recall phase, each participant recalled objects in turn according to three object criteria. In each case, they were instructed to "Select the favourite object of yours which you value with regard to ...," with the instruction concluding in three different ways, as follows: for appearance, ". . . appearance (for example, clothing, or a picture, or a car)"; for usability, ". . . some activity (for example, sports kit, or a computer, or a cooking utensil)"; and for memory, “. . . its meaning for you (for example, a souvenir, or something that's a source of satisfaction, or a talking-point)." The order of presentation of these three selections was balanced across participants. After three selections, a fourth, unrestricted selection was cued: "Please select the favourite object of yours of any type, other than the three objects which you have already listed."

For each of the four recalled objects, participants were asked to respond first by identifying the object (though it was indicated that the identity of the object could be withheld if it were thought to be too personal), and then with the length of time that they had had the object. Next, they made assessments of the salience of five different aspects of the object, in each case on a 7-point scale from 1 (not at all important) to 7 (extremely important). The first three scales matched the three restrictive selection criteria - appearance salience ("the physical appeal of the object"), usability salience ("the ease of using the object") and memory salience ("the significance to you of the object"). Finally, for each object, participants responded on the same 7-point scale regarding social salience ("other people's opinion of the object") and financial salience ("the financial value of the object").

After all responses had been made for individual objects, the choice phase commenced and the relative values of all the recalled objects were established. Adapting a scenario described by Norman (2004, p. 52), the participant was instructed to "list the order in which you would want the objects . . to be saved" from a burning building. The four responses were then transformed, as indicated earlier, to yield personal values, $v$, for the objects, ranging from 1 for the first choice to 0 for the last choice.

\section{Results}

Object choice as a function of recall criteria. Table 1 shows mean personal values for objects recalled according to the four different criteria. It can be seen that objects selected according to the memory criterion had the highest mean personal value. A Friedman test on the choices among the four objects confirmed that personal values differed significantly across the four criteria $\left[\chi^{2}(3, N=\right.$ $73)=35.35, p<.001]$. A complementary analysis focused only on the distribution of objects with highest personal value (i.e., those which were chosen first from among four objects), also shown in Table 1. The numbers of participants for whom an object selected according to the appearance, usability, memory, and unrestricted criteria had the highest value were, respectively, 8, 7, 39, and 20 . These frequencies differed significantly among themselves $\left[\chi^{2}(3, N=74)=35.95, p<.001\right]$. When the group most often chosen first, memory objects, was compared with the appearance and usability objects, the proportion of the total which it comprised, $72.2 \%$, was significantly greater than (indeed, more than twice as high as) the $33.3 \%$ which it would have comprised, had objects with highest value been uniformly distributed across the three categories with restrictive criteria $\left[\chi^{2}(1, N=54)=\right.$ $36.75, p<.001]$.

Object duration. The mean lengths of time (in years) that participants had possessed the objects were 1.54

Table 1

Mean Object Values and Frequencies of First-Choice Objects for Different Recall Criteria in Experiment 1 Recall Criterion

\begin{tabular}{|c|c|c|c|c|c|c|c|c|}
\hline \multirow[b]{2}{*}{ Measure } & \multicolumn{2}{|c|}{ Appearance } & \multicolumn{2}{|c|}{ Usability } & \multicolumn{2}{|c|}{ Memory } & \multicolumn{2}{|c|}{ Unrestricted } \\
\hline & $M$ & $S D$ & $M$ & $S D$ & $M$ & $S D$ & $M$ & $S D$ \\
\hline Object value & .347 & .335 & .397 & .336 & .735 & .319 & .521 & .381 \\
\hline Frequency & \multicolumn{2}{|c|}{8} & \multicolumn{2}{|c|}{7} & \multicolumn{2}{|c|}{39} & \multicolumn{2}{|c|}{20} \\
\hline
\end{tabular}


$(S D=1.85), 2.65(S D=2.92), 5.32(S D=6.13)$, and $3.37(S D=3.88)$ for objects selected according to the appearance, usability, memory, and unrestricted criteria, respectively. An ANOVA showed that mean duration varied significantly across the four categories $[F(3,213)=$ $\left.13.13, p<.001, \eta^{2}=.16\right]$. Pairwise comparisons confirmed that memory objects had been possessed significantly longer than each of the other three types. In the reported a posteriori comparisons, Tukey's HSD test was used $(p<.01)$.

Object saliences. Table 2 shows mean saliences for objects selected according to each of the criteria. A first analysis was carried out to examine whether, as expected, instructions to select on the basis of appearance, usability, and memory had led to matching peaks in the salience responses. Thus a two-way ANOVA on the salience data examined appearance, usability, and memory levels within salience type and selection-criterion variables. There was a significant effect of salience type $[F(2,142)=8.51, p<$ $\left..001, \eta^{2}=.11\right]$, but not of selection criterion $[F(2,142)=$ 3.02] with, more importantly, a significant interaction between the two $\left[F(4,284)=77.10, p<.001, \eta^{2}=.52\right]$. As can be seen in Table 2, for each salience type the highest level of response occurred for the matching type of selection criterion; pairwise HSD comparisons confirmed that, in all three cases, the mean salience response was significantly higher for the matching selection criterion than for the two nonmatching selection criteria.

Further ANOVAs showed that there were significant differences among objects selected according to the appearance, usability, and memory selection criteria in terms both of social salience $\left[F(2,146)=33.04, p<.001, \eta^{2}=\right.$ $.31]$ and of financial salience $[F(2,146)=20.74, p<$ $\left..001, \eta^{2}=.22\right]$. Pairwise HSD comparisons showed that social salience was significantly higher for appearance objects than for both usability objects and memory objects, and that financial salience was significantly lower for memory objects than for both appearance objects and usability objects.

Predicting choice among objects. A regression analysis was carried out to examine variables potentially predictive of the outcome of choosing among objects, on data combined across selection criteria (i.e., including data for all objects). Stepwise multiple regression was carried out across objects, with personal value predicted on the basis of object duration; appearance, usability, and memory salience; and social and financial salience. The highest correlate of object value was memory salience $[r(292)=.340$ (Spearman $\left.\left.r_{\mathrm{S}}=.374\right), p<.001\right]$, which was thus entered first by the analysis $\left[F(1,286)=36.59, p<.001, \Delta R^{2}=\right.$ .113]; second entered was object duration $[F(1,285)=$ $\left.14.52, p<.001, \Delta R^{2}=.043\right]$; third was financial salience $\left[F(1,284)=5.30, p<.05, \Delta R^{2}=.015\right]$; and fourth was social salience $\left[F(1,283)=5.43, p<.05, \Delta R^{2}=.016\right]$. The best prediction of personal value was $v=.094+.066$ memory +.017 duration +.031 financial -.028 social, $R^{2}=.187$, with memory salience accounting for $60.4 \%$ of the systematic variance. Williams tests showed that the
Table 2

Mean Object Saliences for Different Recall Criteria in Experiment 1

\begin{tabular}{|c|c|c|c|c|c|c|c|c|}
\hline \multirow[b]{3}{*}{ Salience } & \multicolumn{8}{|c|}{ Recall Criterion } \\
\hline & \multicolumn{2}{|c|}{ Appearance } & \multicolumn{2}{|c|}{ Usability } & \multicolumn{2}{|c|}{ Memory } & \multicolumn{2}{|c|}{ Unrestricted } \\
\hline & $M$ & $S D$ & $M$ & $S D$ & $M$ & $S D$ & $M$ & $S D$ \\
\hline Appearance & 6.24 & 1.12 & 3.99 & 1.70 & 4.68 & 1.85 & 5.03 & 1.82 \\
\hline Usability & 4.29 & 1.96 & 5.99 & 1.37 & 3.24 & 2.34 & 5.01 & 1.85 \\
\hline Memory & 4.92 & 1.77 & 4.61 & 1.73 & 6.53 & 0.92 & 5.38 & 1.91 \\
\hline Social & 4.84 & 1.54 & 2.99 & 1.61 & 3.11 & 1.74 & 3.18 & 1.69 \\
\hline Financial & 3.47 & 1.90 & 3.70 & 1.87 & 2.14 & 1.64 & 3.08 & 1.99 \\
\hline
\end{tabular}

correlation of object value with memory salience was significantly greater $(p<.05)$ than the correlation with each of the other variables, except that with object duration, for which $\left[r(290)=.294\left(r_{\mathrm{S}}=.248\right), p<.001\right]$. In addition, pairwise analyses indicated that memory salience was positively related to object duration $[r(292)=.303, p<$ $.001]$; was not significantly related to appearance salience $[r(295)=-.027]$ or social salience $[r(295)=-.003]$; and was negatively related to usability salience $[r(294)=$ $-.344, p<.001]$ and financial salience $[r(295)=-.239$, $p<.001]$.

Object identities. Finally, the identities of the objects recalled in the first phase of the experiment may be examined. For this, the objects were grouped into a set of 25 categories, constructed so as to accommodate them exhaustively. (The object categories and their incidences are shown in the Appendix.) Participants withheld the identities of only $2.4 \%$ of the objects. One category was permitted to be nested within another (e.g., laptop within computer and ring within jewelry) if a relatively large number of responses referred explicitly to the subordinate category. It can be seen that the incidences of the different object categories differed considerably across recall criteria; when the object categories were combined into six larger classes to ensure expected cell frequencies $\geq 5$, then $\chi^{2}(15, N=289)=154.77$, though the tabulated $p<.001$ is only approximated, owing to the repeated measures.

\section{Discussion}

The results of this experiment provided evidence that the property of an object which we value more highly than any other is its ability to evoke our memories. The primary importance of memory linkage in comparison with appearance and usability was directly indicated in two separate ways. First, examination of different recall criteria showed that the objects which were on average most highly valued in participants' choices were those selected according to their meanings for the participants, as opposed to those selected according to their values in relation to activities or appearances, or according to any other criterion. Second, regression analysis of responses regarding all objects, combined across selection criteria, showed that an object's mnemonic salience was the most important predictor of the object's personal value, ahead of five other possible factors. These included not only the usability salience and the appearance salience of the 
object, but also its social salience and financial salience, and (though not significantly) the duration of its possession. Indeed, the financial salience of selected objects was found to be significantly higher for objects selected according to both the usability and appearance criteria than for those selected according to the memory criterion.

Although the results of the present experiment were thus consistent in the emphasis they placed on memory linkage in choosing among objects, there were two areas of its design which in principle may have allowed alternative interpretation. First, a relatively broad specification of memory linkage had been adopted, consistent with the characterization by Norman (2004) of reflective processing. In case this latitude was important, it seemed advisable in a second experiment also to investigate selection according to a narrower interpretation, focusing solely on memory.

Second, the examples of objects which had been provided in the Experiment 1 instructions turned out to differ considerably from participants' own responses. Thus, in the case of objects selected on the basis of memory linkage, the examples taken from Norman (2004) consisted of a souvenir, a source of satisfaction, and a talking point. However, for this criterion, the types of objects which participants most frequently recalled in practice were jewelry (including rings), toys, and photographs. In Experiment 2, therefore, the examples for each type of criterion which were included in the instructions were changed to reflect the actual responses in Experiment 1.

\section{EXPERIMENT 2}

In this experiment, the specification of the memory criterion was narrowed and the usability and appearance criteria subsumed within unrestricted selection. In addition, the examples of valued objects which were provided were based on the most frequent responses in the relevant classes of Experiment 1.

\section{Method}

Participants. There were 97 participants ( 83 female), first-year students at the Universities of Warwick and Oxford. Mean age was 19.7 years $(S D=3.7)$.

Design and Procedure. In the recall phase, each participant recalled objects in turn, according to two object criteria. In both cases, they were instructed to "Select the favourite object of yours which you value primarily. ..," with the instruction concluding as follows: for memory objects, ". . . with regard to the memories it evokes for you (for example, a childhood toy, or a photograph album, or a special gift)"; for unrestricted objects, ". . . for reasons other than the memories it evokes for you (for example, a computer, or an item of clothing, or a car)." The order of the two selections was balanced across participants. For each selection, participants were asked the same questions as in Experiment 1 and made the same set of judgments. The procedure again concluded with a choice phase in which participants responded by choosing in order between the objects from the first phase.

\section{Results}

Object choice as a function of recall criteria. The number of participants who allocated highest personal value to an object selected according to the memory criterion (i.e., chose it first) was $75(77.3 \%)$, which was significantly greater than the $22(22.7 \%)$ who allocated highest personal value to an unrestricted-selection object $\left[\chi^{2}(1, N=97)=28.96, p<.001\right]$.

Object duration. An ANOVA showed that the mean length of time that memory objects had been possessed $(M=6.65$ years, $S D=6.68)$ was significantly greater than that for unrestricted objects $(M=2.26$ years, $S D=$ 2.93) $\left[F(1,94)=35.92, p<.001, \eta^{2}=.28\right]$.

Object saliences. Table 3 shows mean saliences for objects selected according to the two criteria. A two-way ANOVA examined appearance, usability, and memory saliences for memory and unrestricted selection criteria. There were significant effects of salience type $[F(2,190)=$ $\left.39.66, p<.001, \eta^{2}=.30\right]$ and of selection category $\left[F(1,95)=12.07, p=.001, \eta^{2}=.11\right]$ together with a significant interaction $\left[F(2,190)=95.02, p<.001, \eta^{2}=\right.$ $.50]$. Pairwise HSD comparisons confirmed that the level of memory salience was significantly higher for the matching than for the nonmatching selection criterion, and also confirmed conversely that levels of appearance salience and usability salience were significantly lower for memory selection than for unrestricted selection. Further ANOVAs showed that, compared with unrestricted selection, memory selection was associated with lower levels both of social salience $\left[F(1,96)=5.26, p<.05, \eta^{2}=.05\right]$ and of financial salience $\left[F(1,96)=96.00, p<.001, \eta^{2}=.50\right]$.

Predicting choice among objects. Stepwise multiple regression was carried out in order to predict object choice on the basis of object duration and saliences, for all objects. The highest correlate of object value was memory salience $\left[r(193)=.483\left(r_{\mathrm{S}}=.511\right), p<.001\right]$, which was thus entered first by the analysis $[F(1,189)=55.95$, $\left.p<.001, \Delta R^{2}=.228\right]$; second entered was appearance salience $\left[F(1,188)=9.48, p<.01, \Delta R^{2}=.037\right]$; and the third was usability salience $[F(1,187)=3.99, p<.05$, $\left.\Delta R^{2}=.015\right]$. The best prediction of personal value was $v=.114+.124$ memory -.041 appearance -.032 usability, $R^{2}=.281$, with memory salience accounting for $81.1 \%$ of the systematic variance. Williams tests showed that the correlation of object value with memory salience was significantly greater $(p<.05)$ than the correlation with each of the other variables. In addition, pairwise analyses indicated that memory salience was positively related to object duration $[r(191)=.157, p<.05]$; was

Table 3

Mean Object Saliences for Different Recall Criteria in Experiment 2

\begin{tabular}{|c|c|c|c|c|}
\hline \multirow[b]{3}{*}{ Salience } & \multicolumn{4}{|c|}{ Recall Criterion } \\
\hline & \multicolumn{2}{|c|}{ Memory } & \multicolumn{2}{|c|}{ Unrestricted } \\
\hline & $M$ & $S D$ & $M$ & $S D$ \\
\hline Appearance & 4.00 & 2.03 & 5.01 & 1.84 \\
\hline Usability & 2.99 & 2.00 & 5.36 & 1.59 \\
\hline Memory & 6.67 & 0.74 & 4.67 & 1.73 \\
\hline Social & 3.04 & 1.85 & 3.63 & 1.69 \\
\hline Financial & 1.82 & 1.30 & 3.82 & 1.73 \\
\hline
\end{tabular}


not significantly related to appearance salience $[r(193)=$ $-.108]$ or social salience $[r(193)=-.043]$; and was negatively related to usability salience $[r(193)=-.394$, $p<.001]$ and financial salience $[r(193)=-.388, p<$ $.001]$.

\section{Discussion}

The principal results of this experiment confirmed those of Experiment 1. The mnemoactive capacity of an object was again shown to be of primary importance, even though it was more narrowly defined in terms of evoked memories than in Experiment 1. Objects recalled according to this criterion were found on average to be more valued than objects selected on any alternative basis. In addition, regression analysis of the responses regarding all objects showed that an object's memory salience was the most important predictor of participants' choices, significantly ahead of five other possible factors. The financial salience of selected objects was again found to be significantly lower for objects selected according to the memory criterion than it was for other objects.

Although the results of Experiments 1 and 2 were highly consistent, it is logically possible that the observed primacy of memory linkage in determining an object's value does not generalize beyond the relatively restricted population from which both experiments drew their samples. Participants in both of the first two studies were predominantly young, female British adults. It is possible that different results may hold true for older participants, male participants, or participants from a different country, so a further experiment was carried out to explore these factors. Further, it is possible in principle that the primacy of memory linkage is dependent upon the individual's general level of financial satisfaction (e.g., among those who feel worse off financially, primacy might be eroded by a greater concern with object expense), and the new experiment allowed this possibility also to be examined.

\section{EXPERIMENT 3}

A procedural change introduced in this experiment was the omission during the recall phase of any object examples for the different selection criteria. In Experiment 1, participants had been provided with examples drawn from Norman (2004). In Experiment 2, to avoid the possibility of a theoretical bias, they had been provided instead with examples drawn from the most frequent responses in Experiment 1, and this change had not in fact influenced the pattern of results. Nevertheless, the provision of any examples at all may have had the potential to bias participants' responses in some way, so in the present experiment the examples were removed entirely. The three selection criteria of appearance, usability, and memory linkage were investigated, with participants recalling two objects for each, instead of one.

\section{Method}

Participants. There were 117 participants, all of whom were U.S. citizens.
Design and Procedure. There were two between-participants variables, gender and age. With regard to gender, there were 69 female and 48 male participants. With regard to age, there were 66 younger adults (age 25 or less; $M=21.7, S D=1.6$ ), and 51 older adults (age 30 or above; $M=46.7, S D=9.3$ ). Most of the younger adults were students, and most of the older adults were professionally employed (e.g., as managers and teachers). Testing was carried out mainly in the U.S., with some in the U.K.

In the recall phase, each participant selected objects in turn according to three object criteria. In each case, they were instructed to "Select the two favourite objects of yours which you value with regard to. .. ," with the instruction concluding in three different ways, as follows: for appearance, ". . . their appearances"; for usability, ". . . their uses"; for memory, ". . . the memories they bring to mind." No examples of possible objects were provided. The order of presentation of the three selection criteria was balanced across participants. For each selection, participants were asked the same questions as in the previous experiments and made the same set of judgments (the description of memory salience was modified to "the link to your past of the object"). As in the two previous experiments, the choice phase followed, at which point the relative values of the participant's six recalled objects were established from the responses to the instruction "list the order in which you would want the objects

. to be saved." Finally, the participant's level of financial satisfaction was assessed via the question "To what extent do you feel financially well off?" Responses were on a 7-point scale from 1 (not at all well off) to 7 (extremely well off).

\section{Results}

Object choice as a function of recall criteria. The top row of Table 4 shows the mean values that were associated with objects recalled according to the three different criteria. Objects selected on the basis of their linkage to memory were associated with considerably higher value than the two other types, and a Friedman test confirmed that personal values differed significantly across the three criteria $\left[\chi^{2}(2, N=115)=51.00, p<.001\right]$. The participants were also divided into two groups, with either low $(n=41)$ or high $(n=74)$ financial satisfaction scores, defined as scores below or above the mean, respectively. However, for both groups, all three means of the values remained very close to the overall means shown in Table 4 - within .010 in each case. Friedman tests were significant for both groups.

Instead of considering all six objects, a complementary analysis focused on the single object which was allocated the highest personal value (i.e., chosen first) by each participant. The numbers of participants for whom an object selected according to its appearance, usability, and

Table 4

Mean Object Values for Different Recall Criteria and Groups in Experiment 3

\begin{tabular}{|c|c|c|c|c|c|c|}
\hline \multirow[b]{3}{*}{ Group } & \multicolumn{6}{|c|}{ Recall Criterion } \\
\hline & \multicolumn{2}{|c|}{ Appearance } & \multicolumn{2}{|c|}{ Usability } & \multicolumn{2}{|c|}{ Memory } \\
\hline & $M$ & $S D$ & $M$ & $S D$ & $M$ & $S D$ \\
\hline All & .457 & .223 & .361 & .211 & .683 & .223 \\
\hline Female & .435 & .205 & .346 & .209 & .719 & .210 \\
\hline Male & .487 & .247 & .383 & .216 & .630 & .232 \\
\hline Younger & .436 & .214 & .393 & .232 & .671 & .232 \\
\hline Older & .484 & .236 & .317 & .175 & .699 & .211 \\
\hline
\end{tabular}


Table 5

Mean Object Durations (in Years) for Different Recall Criteria and Groups in Experiment 3

\begin{tabular}{|c|c|c|c|c|c|c|}
\hline \multirow[b]{3}{*}{ Group } & \multicolumn{6}{|c|}{ Recall Criterion } \\
\hline & \multicolumn{2}{|c|}{ Appearance } & \multicolumn{2}{|c|}{ Usability } & \multicolumn{2}{|c|}{ Memory } \\
\hline & $M$ & $S D$ & $M$ & $S D$ & $M$ & $S D$ \\
\hline All & 6.78 & 7.34 & 5.10 & 4.51 & 10.60 & 7.93 \\
\hline Female & 7.24 & 8.20 & 5.25 & 4.85 & 11.50 & 7.84 \\
\hline Male & 6.06 & 5.77 & 4.87 & 3.97 & 9.21 & 7.97 \\
\hline Younger & 3.26 & 2.88 & 3.43 & 2.67 & 7.23 & 4.66 \\
\hline Older & 11.47 & 8.75 & 7.33 & 5.44 & 15.09 & 9.14 \\
\hline
\end{tabular}

memory criteria had the highest value were, respectively, 26,21 , and 68 . These frequencies differed significantly among themselves $\left[\chi^{2}(2, N=115)=34.77, p<.001\right]$. When the objects that were most frequently chosen first, memory objects, were compared with appearance and usability objects, the proportion of the total which they comprised, $59.1 \%$, was significantly greater than the $33.3 \%$ which they would have comprised had objects chosen first been uniformly distributed across the three criteria $\left[\chi^{2}(1\right.$, $N=115)=34.44, p<.001]$.

Two different approaches to investigating the possible effects of gender and of age on personal value were adopted. In the first approach, the preceding type of analysis was carried out on particular groups of participants. Table 4 shows mean values separately for female and male participants and for younger and older adults. It can be seen that, in each case, the highest value was attached to the memory criterion. Friedman tests confirmed significant differences in personal value across the three criteria for each of the groups $\left[\chi^{2}(2, N=68)=43.90, p<.001\right.$ for the female group; $\chi^{2}(2, N=47)=10.01, p<.01$ for the male group; $\chi^{2}(2, N=66)=24.68, p<.001$ for the younger group; and $\chi^{2}(2, N=49)=30.21, p<.001$ for the older group].

In the second type of approach, a concurrent analysis of effects was made on the basis of a parametric assumption by means of a three-way split-plot ANOVA on all selection responses. The analysis confirmed a significant effect of selection criterion $[F(2,222)=39.44, p<.001$, $\left.\eta^{2}=.26\right]$; pairwise HSD comparisons demonstrated that memory objects were significantly more valued than both appearance and usability objects, but did not indicate a significant difference between the latter two types of object. There was no significant interaction between selection criterion and gender $[F(2,222)=2.23]$ or between selection criterion and age $[F(2,222)=1.37]$, nor was there a significant three-way interaction between selection criterion, gender, and age $[F(2,222)<1]$.

Object duration. Table 5 shows the mean lengths of time for which participants had possessed the objects selected according to each of the three criteria. A three-way split-plot ANOVA showed that the mean time of possession varied significantly across the three criteria $[F(2,216)=$ $37.01, p<.001, \eta^{2}=.26$ ]; pairwise HSD comparisons showed that memory objects had been possessed significantly longer than both appearance and usability ob- jects, which did not differ significantly from each other. There was no significant effect of gender $[F(1,108)=$ $1.71]$ but, as expected, the mean time of possession was significantly greater for older than for younger participants $\left[F(1,108)=61.38, p<.001, \eta^{2}=.36\right]$. There was a significant interaction between selection criterion and age group $\left[F(2,216)=6.58, p<.01, \eta^{2}=.06\right]$, but this may be interpreted as a floor effect. For the appearance and memory criteria, the durations for younger participants were, respectively, 8.21 and 7.86 years fewer than those for older participants; but for the usability criterion, the mean duration for older participants was itself only 7.33 years, ensuring a smaller reduction in duration for younger participants than in the other two cases. Finally, there was no significant interaction between selection criterion and gender $[F(2,216)<1]$ or three-way interaction $[F(2,216)=2.90]$.

Object saliences. Table 6 shows mean saliences, averaged across all participants, for objects selected according to each of the criteria. A four-way split-plot ANOVA examined appearance, usability, and memory levels within salience type and selection criterion variables, together with gender and age. There were significant effects of type of judged salience $\left[F(2,226)=5.89, p<.01, \eta^{2}=.05\right]$ and type of selection criterion $\left[F(2,226)=6.47, p<.01, \eta^{2}=\right.$ $.05]$ with, importantly, a strong interaction between them $\left[F(4,452)=161.49, p<.001, \eta^{2}=.59\right]$. As expected, for each type of judged salience the highest value occurred for the matching type of selection criterion; tests of simple main effects confirmed that the variation between the three different types of selection criterion was significant in each case [all $F_{\mathrm{s}}(2,112) \geq 81.03, p<.001, \eta^{2} \geq .59$ ] and pairwise comparisons confirmed for each type of salience that the mean salience was significantly higher for the matching recall criterion than for the other two recall criteria (all $p \mathrm{~s}<.001$, with Bonferroni procedure). Though there was not a significant effect of participant age $[F(1,113)=$ $3.10]$, there was one of gender $[F(1,113)=4.04, p<.05$, $\left.\eta^{2}=.04\right]$ with female responses higher (by $M=0.23$ ) than male responses. Gender also interacted significantly with the judged salience and selection criterion variables $\left[F(4,452)=2.46, p<.05, \eta^{2}=.02\right]$; there was a possible range-effect interpretation of this three-way interaction because the average amount by which female scores exceeded male scores was greater for the three matching cases $(M=0.45)$, which had relatively high values (see

Table 6

Mean Object Saliences for Different Recall Criteria in Experiment 3

\begin{tabular}{|c|c|c|c|c|c|c|}
\hline \multirow[b]{3}{*}{ Salience } & \multicolumn{6}{|c|}{ Recall Criterion } \\
\hline & \multicolumn{2}{|c|}{ Appearance } & \multicolumn{2}{|c|}{ Usability } & \multicolumn{2}{|c|}{ Memory } \\
\hline & $M$ & $\overline{S D}$ & $M$ & $S D$ & $M$ & $S D$ \\
\hline Appearance & 5.97 & 1.10 & 4.14 & 1.50 & 4.03 & 1.73 \\
\hline Usability & 3.80 & 1.74 & 6.17 & 0.97 & 3.01 & 1.69 \\
\hline Memory & 4.50 & 1.82 & 3.09 & 1.88 & 6.46 & 0.92 \\
\hline Social & 3.79 & 1.63 & 2.80 & 1.39 & 2.50 & 1.35 \\
\hline Financial & 3.13 & 1.75 & 2.97 & 1.63 & 1.88 & 1.26 \\
\hline
\end{tabular}


Table 6), than it was for the six nonmatching cases $(M=$ 0.12 ), which had relatively low values. Finally, participant age interacted significantly with type of judged salience $\left[F(2,226)=4.75, p=.01, \eta^{2}=.04\right]$, with responses for memory salience higher (by $M=0.07$ ) for younger than for older participants, but responses for appearance salience and for usability salience higher (by $M=0.67$ and 0.09 , respectively) for older than for younger participants. No other interactions were significant.

Further three-way split-plot ANOVAs showed that there were significant differences among objects selected according to the appearance, usability, and memory selection criteria in terms both of their social salience $[F(2,226)=$ $\left.38.92, p<.001, \eta^{2}=.26\right]$ and their financial salience $\left[F(2,226)=32.09, p<.001, \eta^{2}=.22\right]$; the means are shown in Table 6 . For financial salience only, there was also a significant interaction between selection type and participant age $\left[F(2,226)=3.85, p<.05, \eta^{2}=.03\right]$, with responses for memory objects higher (by $M=0.13$ ) for older than for younger participants, but responses for appearance objects and for usability objects higher (by $M=$ 0.10 and 0.87 , respectively) for younger than for older participants. This two-way interaction was itself modulated by a significant three-way interaction $[F(2,226)=3.11, p<$ $\left..05, \eta^{2}=.03\right]$, but there was an important three-way consistency in that, for each combination of age and gender, mean financial salience responses were numerically lower for memory objects than for appearance and usability objects; tests of simple main effects confirmed that the variation between the three types of selection criterion was significant for each combination [all $F_{\mathrm{s}}(2,112) \geq 3.65, p<$ $\left..05, \eta^{2} \geq .06\right]$, and pairwise comparisons confirmed that the extent to which the responses for memory objects were lower than those for other objects reached significance in each case (all $p \mathrm{~s}<.05$, with Bonferroni procedure), except for usability objects of older participants (both female and male). Overall, it can be seen in Table 6 that, as in the previous experiments, objects selected according to the memory criterion attracted extremely low responses for financial salience $(M=1.88)$, and further examination showed that the lowest possible response, 1 , was made regarding the financial salience of the majority $(67.1 \%)$ of all memory objects.

Predicting choice among objects. Stepwise multiple regression was carried out in order to predict object choice on the basis of object duration and saliences. The highest correlate of object value was memory salience $[r(686)=$ $\left..379\left(r_{\mathrm{S}}=.391\right), p<.001\right]$, which was thus entered first by the analysis $\left[F(1,645)=108.38, p<.001, \Delta R^{2}=\right.$ .144]; second entered was financial salience $[F(1,644)=$ $\left.7.68, p<.01, \Delta R^{2}=.010\right]$; third was appearance salience $\left[F(1,643)=11.25, p=.001, \Delta R^{2}=.015\right]$; fourth was usability salience $\left[F(1,642)=9.98, p<.01, \Delta R^{2}=.013\right]$; and fifth was social salience $[F(1,641)=7.68, p<.01$, $\left.\Delta R^{2}=.005\right]$. The best prediction of personal value was $v=.382+.051$ memory +.035 financial -.018 appearance -.019 usability -.016 social, $R^{2}=.186$, with memory salience accounting for $77.4 \%$ of the systematic variance. Williams tests showed that the correlation of object value with memory salience was significantly greater $(p<.001)$ than the correlation with each of the other variables. In addition, pairwise analyses indicated that memory salience was positively related to object duration $[r(659)=.364, p<.001]$; was not significantly related to appearance salience $[r(698)=-.061]$ or social salience $[r(698)=-.067]$; and was negatively related to usability salience $[r(694)=-.476, p<.001]$ and financial salience $[r(698)=-.287, p<.001]$.

\section{Discussion}

The results confirmed and considerably extended those of the two previous experiments. Confirming the previous findings, objects chosen on the basis of their linkage to memory were valued more highly than those selected on other criteria and, across all objects, the prediction of object value was dominated by memory salience. Extending the previous findings, they were found to generalize not only across nationality (participants from the U.S. instead of the U.K.) but also across gender and age. The primacy in value of memory linkage was observed among male as well as female participants, and among older as well as younger adults. It was also observed both among those who viewed themselves as financially badly off and those who viewed themselves as well off.

Some significant differences among groups were detected, mainly within the salience responses, but did not affect the principal findings. Thus, with regard to gender, first, salience responses in general were significantly higher for female participants, and, second, in the specific case of financial salience, there was a three-way interaction of effect between gender, age, and selection criterion, of relatively small magnitude but perhaps reflecting complex societal contingencies in the area of finance. With regard to age, there was some evidence that younger adults may be more, rather than less, concerned with the past than older adults because the average level of memory salience, unlike levels of appearance salience and utility salience, was greater for younger than for older participants. In addition, as expected, the average age of selected objects was significantly greater for older than for younger participants.

\section{GENERAL DISCUSSION}

The results of all three experiments were highly consistent in their principal findings, which provided direct support for the proposition that when people choose among the objects in their everyday life, the dominant characteristic of the objects on which they place the greatest value is the capacity to evoke memories. Of two primary sets of analyses, one compared objects selected according to criteria corresponding to the reactive, behavioral, and reflective levels of psychological processing distinguished by Norman (2004), namely, object appearance, object usability, and object linkage to memory, respectively. In Experiment 1, objects selected in terms of their linkage to memory were compared with items selected not only on the basis of appearance and usability but also on the com- 
plementary basis of any other criterion; in Experiment 2, they were compared with the complementary objects only; and in Experiment 3, they were compared with objects selected in terms of appearance and usability only. Notwithstanding this variation in procedure, the mnemoactive objects turned out in each experiment to be significantly more highly valued than the others. In each experiment, more first choices were drawn from the mnemoactive category than from all other categories combined.

A second set of primary analyses attempted to provide an understanding of all choices among objects in terms of six object variables. Three of these were the estimated salience of the object's appearance, its usability, and its linkage to memory. Two more variables involved a wider societal perspective - namely, the object's social salience (importance of other people's opinions) and its financial salience (importance of financial value) - and the final variable was object duration. Again, despite the differences in procedure among the three experiments, their results were consistent. In each experiment, the best predictor of participants' choices among all objects was the extent to which each object had been judged to be linked to memory. Others of the five further variables were additionally predictive within each experiment to a significant, but considerably smaller, extent. Memory salience was responsible for, on average, $72.6 \%$ (range $60.4 \%$ to $80.1 \%$ ) of the total variance systematically accounted for within each experiment.

The outcomes of the two sets of primary analyses within each of three different experiments provided remarkably consistent evidence that, when people choose their most valued objects, the criterion they use is that of linkage to their memories. Appearance, usability, the opinion of others, and financial value all proved much less important than linkage to memory. The strength of the effect is perhaps surprising, since it has sometimes been argued (e.g., Johnson-Laird \& Oatley, 1989; but see Jones \& Martin, 1992) that a natural language's lexicon provides a clear insight into underlying psychological processes. In the present case, however, although the English language has positively valenced descriptors readily available for the other types of property (e.g., beautiful, useful, prestigious, and expensive objects, respectively, for appearance, usability, social, and financial saliences), in the case of linkage to memory it even seems necessary to introduce an appropriate descriptor-mnemoactive objects. What may we learn about the characteristics of mnemoactive objects from the results of these experiments?

First, given the backward temporal reference inherent in memory, it was unsurprising to confirm that objects selected on the basis of memory had on average been possessed significantly longer than those selected on the basis of appearance or usability. However, it did not appear that an object gained greater value simply by reaching a threshold age. In Experiment 3, the appearance and usability objects of the older participants were valued relatively low as usual, even though they had on average been possessed longer than the highly valued memory objects of the younger participants. It is also interesting to note that, because the average age of the older group was 47 years, and the average period of possessing their memory objects was 15 years, the average age of acquisition was approximately 32 years. There is now considerable evidence of a reminiscence bump in the recall of everyday memories (e.g., Rubin \& Berntsen, 2003; Rubin \& Schulkind, 1997), with older people tending to recall preferentially events which occurred in and around their twenties. The present results thus raise the possibility that one source of the reminiscence bump may be a consistency in the presence of mnemoactive objects which elicit memories from a particular phase of people's lives. The suggestion that a period which favors the creation of retrievable memories may also be associated with the acquisition of potentially mnemoactive objects does, however, require strengthening by further empirical investigation.

Second, a logical possibility is that the apparent influence of memory linkage on object choice is mediated via financial value (i.e., enhanced memories might be associated with particularly expensive objects, with choices determined primarily by expense). Contrary to this, however, it was found that the financial salience of objects selected on the basis of their linkage to memory was extremely low throughout (e.g., two thirds of the memory objects in Experiment 3 were placed in the lowest of the seven response categories). Similarly, it was found that, across all objects investigated, there was a significant negative relation between memory salience and financial salience. Finally, it was found in Experiment 3 that the primacy of memory linkage in determining object choice was observed irrespective of whether participants viewed themselves as financially badly off or well off. These findings in combination appear to exclude the possibility that it is underlying financial mediation which is responsible for the observed effect of memory linkage on object choice.

Third, the present results suggest that the primacy of memory linkage in determining object choice is widely distributed among different groups of people. Similar relations among the values of objects selected according to different criteria were observed for both genders and for different nationalities. There was even no significant evidence of an interaction with participant age. This last finding appears at first sight to conflict with the suggestion of Csikszentmihalyi and Rochberg-Halton (1981, p. 61) that objects for older people have "quite a different set of meanings from the ones typically mentioned by younger respondents. Gone is the emphasis on comfort and enjoyment; one finds, instead, important memories, relationships, and past experiences." The evidence from all three of the present experiments, on the other hand, strongly suggests that memory linkage is an important, indeed dominant, determinant of our responses to objects, from at least young adulthood onward. A possible reason for the apparent discrepancy is that Csikszentmihalyi and Rochberg-Halton (1981) included in their study children as young as 8 years. If their data relating only to adults are reanalyzed, it turns out that the proportions of participants who were classified by Csikszentmihalyi and Rochberg-Halton (1981, p. 283) as treating at least one 
object as a memento did not differ significantly between younger $(57.3 \%)$ and older $(62.8 \%)$ participants $\left[\chi^{2}(1\right.$, $N=236)=0.67]$. Whether there are other intergroup variables to which mnemoactive primacy is less impervious remains to be investigated. It would also be valuable to explore further the consistencies of processing associated with mnemoactive objects in a range of psychological domains, particularly that of emotion.

Finally, two broader implications of the present work may be noted. First, the finding that it is the mnemonic rather than the financial characteristics of an object which primarily determine the object's value to its owner may contribute to our understanding of the apparent paradox that wealth as such seems to have only a relatively small effect upon subjective well-being within a society (e.g., Diener \& Biswas-Diener, 2002; Easterlin, 2003). Increased wealth may allow the acquisition of more expensive objects, but the present results show that people's most valued objects are not in fact characterized by expensiveness; price tags appear to be subordinate to memory tags. Nor, by the same token, were people's most valued objects characterized by branding, which was strikingly infrequent in the responses observed in these experiments. In Experiment 1, only three responses referred to brands"my Sony Clié," "iPod," and "Chloé sunglasses"; and in Experiment 2 there were only two such responses - "Cerruti suit" and "etnies (shoes)"-with none of these objects selected for its linkage to memories. Branding plays a central role in the field of advertising (e.g., Kokkinaki $\&$ Lunt, 1999), and the very low rate of branded responses in these experiments - of the order of only $1 \%$ - suggests therefore that people's choices among valued objects are, in general, relatively immune to the effects of advertising. On the other hand, it is possible that participants tended to assume that brands fell outside the remit of the present experiments and, accordingly, that they might become more prominent in people's responses if attempts were made to elicit brand names more specifically.

Second, the primacy of mnemoactive objects among people's possessions is consistent with the possibility that such objects gain their value from their power to unlock otherwise inaccessible involuntary autobiographical memories. Although such memories are not elicited by conscious attempts at retrieval (e.g., Berntsen, 1998; Berntsen $\&$ Hall, 2004), it seems likely that we are able to influence their retrieval indirectly by the deployment of appropriate objects. Indeed, it may be that book contents serve a similar function in the case of involuntary semantic memories (Kvavilashvili \& Mandler, 2004). The characterization of involuntary autobiographical memories appears to provide the possibility of a long-delayed convergence between cognitive science and Proustian accounts of memory functioning. In the case of Proust, literary studies of his work abound, as noted in a recent bibliography (Bales, 2001, p. 230): "The amount of critical studies devoted to Proust is now so huge that only a fraction can be presented here." However, despite the fame of Proust's madeleine episode in À la recherche du temps perdu (Remembrance of things past) (Proust, 1922-1931), it is arguable that rather little about memory has emerged beyond the obvious concern of Proust to highlight its importance to humanity. As noted by Terdiman (1993, p. 152), "For more than seventy years, scholars have rehearsed Proust's salvationist notion of the mnemonic ... Why has discussion of Proustian memory produced so little insight?" From the present perspective, a possible answer to Terdiman's question is that the most important corollary of Proust's analysis of the role of human memory appears to have been generally overlooked. Proust asserted both that a particular object (e.g., a madeleine or a flagstone) may have the power to involuntarily retrieve an individual's memories, and also that the recovery of lost times through memory is of extraordinary value to the individual. Combining these two propositions, we arrive at the corollary that especially high value should be placed upon objects which have the ability reliably to evoke memories. We have been unable to trace any previous formulation of this corollary, but it is remarkably congruent with the empirical findings which we have observed here.

\section{REFERENCES}

Bales, R. (ED.). (2001). The Cambridge companion to Proust. Cambridge: Cambridge University Press.

BARNum, C. M. (2002). Usability testing and research. New York: Longman.

Berntsen, D. (1998). Voluntary and involuntary access to autobiographical memory. Memory, 6, 113-141.

Berntsen, D., \& HaLL, N. M. (2004). The episodic nature of involuntary autobiographical memories. Memory \& Cognition, 32, 789-803.

Bohlmeijer, E., Smit, F., \& Cuijpers, P. (2003). Effects of reminiscence and life review on late-life depression: A meta-analysis. International Journal of Geriatric Psychiatry, 18, 1088-1094.

BREWIN, C. R., DALGLeISH, T., \& JosePH, S. (1996). A dual representation theory of posttraumatic stress disorder. Psychological Review, 103, 670-686.

BROOKER, D., \& DuCE, L. (2000). Wellbeing and activity in dementia: A comparison of group reminiscence therapy, structured goal-directed group activity and unstructured time. Aging \& Mental Health, 4, 354358.

CAPPEliez, P., O'Rourke, N., \& Chaudhury, H. (2005). Functions of reminiscence and mental health in later life. Aging \& Mental Health, 9, 295-301.

CHOAY, F. (2001). The invention of the historic monument (L. M. O'Connell, Trans.). New York: Cambridge University Press. (Original work published 1992)

Csikszentminalyi, M., \& Rochberg-Halton, E. (1981). The meaning of things. New York: Cambridge University Press.

Diener, E., \& Biswas-Diener, R. (2002). Will money increase subjective well-being? Social Indicators Research, 57, 119-169.

EAsterlin, R. A. (2003). Explaining happiness. Proceedings of the $\mathrm{Na}$ tional Academy of Sciences, 100, 11176-11183.

EHLERS, A., \& CLARK, D. M. (2000). A cognitive model of posttraumatic stress disorder. Behaviour Research \& Therapy, 38, 319-345.

Frederick, S., \& LoEWEnSTEIN, G. (1999). Hedonic adaptation. In D. Kahneman, E. Diener, \& N. Schwartz (Eds.), Well-being: The foundations of hedonic psychology (pp. 302-329). New York: Russell Sage.

Gillan, D. J., \& Bias, R. G. (2001). Usability science I: Foundations. International Journal of Human-Computer Interaction, 13, 351-372.

IsAAC, C. L., CuSHWAY, D., \& JoNES, G. V. (2006). Is posttraumatic stress disorder associated with specific deficits in episodic memory? Clinical Psychology Review, 26, 939-955.

JoHNSON-LAIRD, P. N., \& OATLEY, K. (1989). The language of emotions: An analysis of a semantic field. Cogniton \& Emotion, 3, 81-123. 
JoNEs, G. V. (1976). A fragmentation hypothesis of memory: Cued recall of pictures and of sequential position. Journal of Experimental Psychology: General, 105, 277-293.

JoNES, G. V. (1978). Repeated cuing and the structure of recall. British Journal of Mathematical \& Statistical Psychology, 31, 1-10.

Jones, G. V. (2002). Predicability (ease of predication) as semantic substrate of imageability in reading and retrieval. Brain \& Language, 82, 159-166.

Jo NES, G. V., \& MARTin, M. (1992). Conjunction in the language of emotions. Cognition \& Emotion, 6, 369-386.

Jones, G. V., \& Martin, M. (2004). Orientation illusions in memory. In R. F. Pohl (Ed.), Cognitive illusions: A handbook on fallacies and biases in thinking, judgement and memory (pp. 293-308). Hove, U.K.: Psychology Press.

KoKKINAKI, F., \& LunT, P. (1999). The effect of advertising message involvement on brand attitude accessibility. Journal of Economic Psychology, 20, 41-51.

KVAVILASHVILI, L., \& MandLer, G. (2004). Out of one's mind: A study of involuntary semantic memories. Cognitive Psychology, 48, 47-94.

Martin, M., \& Jones, G. V. (1998). Generalizing everyday memory: Signs and handedness. Memory \& Cognition, 26, 193-200.

Martin, M., \& Jones, G. V. (2006). Visual sharpness contingency in recognition accuracy for orientation: Mnemonic illusion suppressed by sensory signature. Journal of Experimental Psychology: General, 135, 542-552.

MARTIN, M., \& Jones, G. V. (2007). Asymptotic learning of alphanumeric coding in autobiographical memory. Cognition, 102, 311-320.

Michalski, S. (1998). Public monuments: Art in political bondage, 1870-1997. London: Reaktion.

NoRman, D. A. (1988). The psychology of everyday things. New York: Basic Books.
Norman, D. A. (2004). Emotional design: Why we love (or hate) everyday things. New York: Basic Books.

Proust, M. (1922-1931). Remembrance of things past (C. K. S. Moncrieff \& S. Hudson, Trans.). London: Chatto \& Windus. (Original work published 1913-1927)

Rubin, D. C., \& Berntsen, D. (2003). Life scripts help to maintain autobiographical memories of highly positive, but not highly negative, events. Memory \& Cognition, 31, 1-14.

Rubin, D. C., \& SCHulKIND, M. D. (1997). The distribution of autobiographical memories across the lifespan. Memory \& Cognition, 25, 859-866.

Shafir, E., \& LeBoeuf, R. A. (2002). Rationality. Annual Review of Psychology, 53, 491-517.

TeRDIMAN, R. (1993). Present past: Modernity and the memory crisis. Ithaca: Cornell University Press.

Williams, J. M. G. (1996). Depression and the specificity of autobiographical memory. In D. C. Rubin (Ed.), Remembering our past: Studies in autobiographical memory (pp. 244-267). Cambridge: Cambridge University Press.

Williams, J. M. G., Healy, H. G., \& Ellis, N. C. (1999). The effect of imageability and predicability of cues in autobiographical memory. Quarterly Journal of Experimental Psychology, 52A, 555-579.

\section{NOTE}

1. The English language appears to lack an existing word to refer specifically to the elicitation of mnemonic processing (e.g., evocative is as likely to refer to the accessing of emotion as of memory). Mnemoactive derives from a mixture of Greek (mnemo-) and Latin (-active) morphemes, sharing this property with many other useful words, such as psychoactive and television.

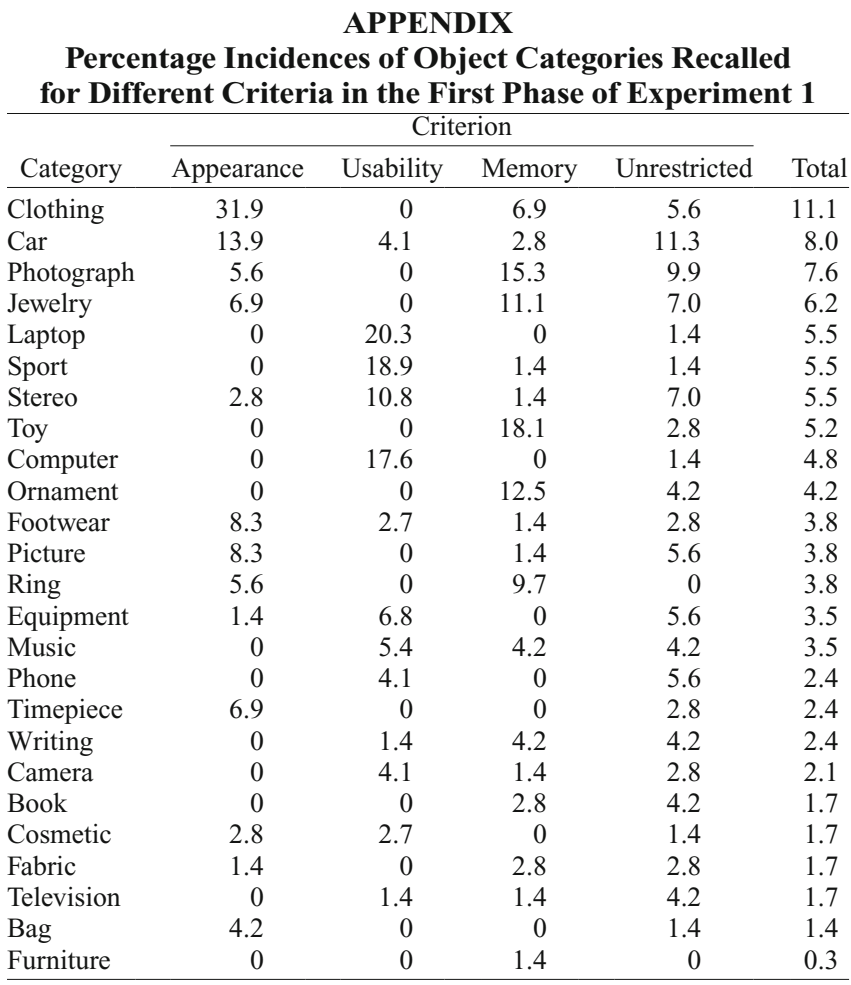

(Manuscript received November 11, 2004; revision accepted for publication October 13, 2005.) 